\title{
MU radar observations of tropopause variations by using clear air echo characteristics
}

\author{
E. Hermawan, T. Tsuda, and T. Adachi \\ Radio Atmospheric Science Center, Kyoto University, Uji, Kyoto 611, Japan \\ (Received August 12, 1996; Revised December 24, 1997; Accepted December 26, 1997)
}

\begin{abstract}
We present in this paper the characteristics of clear air echoes revealed by the MU radar experiments in Shigaraki, Japan $\left(34^{\circ} 51^{\prime} \mathrm{N}, 136^{\circ} 06^{\prime} \mathrm{E}\right)$. In particular, we study a relation between atmospheric stability, represented by Brunt Väisälä frequency squared, $N^{2}$, and both the vertical echo power and the aspect sensitivity. On August 24-25, 1991, echo power was collected by steering the zenith angle of the antenna beam of the MU radar from the zenith to $28^{\circ}$ with a step of $2^{\circ}$. Aspect sensitive echoes were detected in the lower stratosphere and some regions in the troposphere. We found that a ratio of vertical echo power to oblique echo power at $10^{\circ}$ can represent the magnitude of aspect sensitivity. We compared profiles of both the vertical echo power and the aspect sensitivity with $N^{2}$, inferred from a radiosonde sounding at the radar site. Cross correlation analysis indicates that a rapid increase of both vertical echo power and the aspect sensitivity near the tropopause usually coincides with a step-wise enhancement of $N^{2}$.

We also analyzed four other MU radar observations, continued 4-5 days each, and obtained a statistical results that the mean CCF values between profiles of $N^{2}$ and vertical echo power and the aspect sensitivity are 0.89 and 0.86 , respectively. Their mean lag distance was about $71 \mathrm{~m}$ and $134 \mathrm{~m}$, with a standard deviation of $77 \mathrm{~m}$ and 176 $\mathrm{m}$, respectively. That is, the increase in the vertical echo power and the aspect sensitivity generally occurred slightly higher altitude relative to a sharp increase in $N^{2}$. However, we also found some exceptional cases when the lag distance was as large as several hundred meters or even negative.
\end{abstract}

\section{Introduction}

It is generally recognized that the detailed time variation of tropopause structure is very important for studies of dynamical atmospheric properties, such as non linear wave processes and vertical transport of minor constituents. Indeed, recent developments in atmospheric chemistry suggest that the lowermost stratosphere and upper troposphere are more important for global chemical processes than was formerly thought (Holton et al., 1995).

The tropopause height is operationally determined by a conventional technique, represented by a rawinsonde observation once to four times a day. However, its time resolution is not good enough to estimate fluctuations caused by short-period disturbances, such as atmospheric waves. Therefore, we are interested in application of a remotesensing technique for tropopause detection.

In middle latitudes, there is significant seasonal and dayto-day variation in the tropopause structure. The mean tropopause height over Shigaraki, Japan $\left(34^{\circ} 51^{\prime} \mathrm{N}, 136^{\circ} 06^{\prime}\right.$ E) varies from about $11 \mathrm{~km}$ in winter to $15 \mathrm{~km}$ in summer (Tsuda et al., 1991). Especially in winter months, the tropopause height often changes by as much as 4 or $5 \mathrm{~km}$ within a few days, affected by a passage of planetary scale disturbances. Under these circumstances the tropopause is not always well defined, since a front and multiple stable layers often confuse the classical picture of a single distinct boundary between the troposphere and stratosphere (e.g., Gage and Green, 1979).

Copy right (C) The Society of Geomagnetism and Earth, Planetary and Space Sciences (SGEPSS); The Seismological Society of Japan; The Volcanological Society of Japan; The Geodetic Society of Japan; The Japanese Society for Planetary Sciences.
An MST (mesosphere-stratosphere-troposphere) radar detects radiowave scattering by the refractive index fluctuations in a non-precipiting atmosphere. The MST radar echoes can be considered to arise from variations of the refractive index in the spatial volume defined by the transmitted pulse width and the antenna beam. For the $1-100 \mathrm{~km}$ altitude region these variations are attributed to a number of factors. The predominant factors include variations due to turbulence in humidity, temperature (or atmospheric density), and electron density. The relative contribution of these factors are strongly height dependent (Balsley, 1981).

In addition to the turbulent Bragg scattering, enhanced VHF echoes are received from a horizontally stratified atmospheric layer when the radar beam is steered into the vertical direction. This mechanism requires a spatial coherence of the refractive index structure transverse to the radar wave vector (Balsley, 1981).

It has been reported by Tsuda et al. (1986) that profiles of both isotropic turbulent scattering and specular reflection are closely related to the background atmospheric stability. Therefore, the sharp increase in Brunt Väisälä frequency squared, $N^{2}$, near the tropopause is associated with the enhancement of clear air echo intensity. Earlier studies detected a correlation between the tropopause and the altitude of sharp increase in vertical echo power or aspect sensitivity (Gage and Green, 1979, 1982; Röttger, 1980; Hocking et al., 1991). However, a detailed comparison between the $N^{2}$ profile and echo power profiles has not been fully investigated yet. In this study, we compare these profiles with a height resolution as good as $150 \mathrm{~m}$, and aim to find a statistical result on a possible height discrepancy 
between the increase in $N^{2}$ and echo power.

We first review in Section 2 fundamental characteristics of clear air echoes, such as isotropic turbulence scattering and specular reflection. In Section 3, we present a brief description of the MU (middle and upper atmosphere) radar, together with observation techniques for use of clear air echoes, focusing on the aspect sensitivity. We also present in this Section a method for comparison between $N^{2}$ and vertical echo power and aspect sensitivity using a cross correlation function (CCF). Then, in Section 4 we apply this technique for larger data-sets, collected in February 1987, June 1991, 1993 and 1994, in order to obtain a statistical result. Finally, we describe the summary and conclusions of this study in Section 5.

\section{Fundamental Characteristics of Clear Air Echo}

In this section we briefly introduce fundamental characteristics of isotropic turbulence scattering and specular reflection, which account for the clear air echoes detected with the MU radar. Further, we discuss their relationship to the $N^{2}$ which is an index of atmospheric stability.

\subsection{Isotropic turbulence scattering}

The radar equation for isotropic turbulence scattering can be described as follows (e.g., Gage and Balsley, 1980):

$$
P_{s}=\frac{\pi}{64} \frac{P_{t} A_{e} \Delta r}{r^{2}} \eta_{\text {turb }}
$$

where $P_{s}, P_{t}$ and $A_{e}$ are the received power, the transmitted power and the effective area of the antenna, respectively. While, $r$ and $\Delta r$ are the range and the vertical extent of the volume given by half of radar pulse length, respectively. The volume radar reflectivity, $\eta_{\text {turb }}$ for turbulence Bragg scattering is given as follows (Ottersten, 1969; Green et al., 1979; Hocking and Röttger, 1983; Hocking, 1985):

$$
\eta_{\text {turb }}=0.38 \lambda^{-1 / 3} C_{n}^{2}
$$

where $\lambda$ is the radar wavelength and $C_{n}^{2}$ is the refractive index structure constant, which depends upon the outer scale of turbulence, $L_{o}$, and the mean gradient of refractive index, $M$ (Tatarskii, 1971):

$$
C_{n}^{2}=2.8 L_{o}^{4 / 3} M^{2}
$$

Note that $M$ for a dry neutral atmosphere, which is the region of interest in the present study, can be approximated as follows (Ottersten, 1969):

$$
M \propto \rho N^{2}
$$

where $\rho$ is the air density. Furthermore, $L_{o}{ }^{4 / 3}$ was derived as (Hocking, 1985):

$$
L_{o}^{4 / 3}=0.25 \varepsilon^{2 / 3} N^{-2}
$$

where $\varepsilon$ is the turbulence energy dissipation rate. Substituting Eqs. (3) and (5) into Eq. (2), we find:

$$
\eta_{\text {turb }} \propto \rho^{2} \varepsilon^{2 / 3} N^{-2}
$$

\subsection{Specular reflection}

Considering a case of a one-way transmission from an antenna to its mirror image located at a distance $2 r$, the radar equation for a specular reflection was derived as (e.g., Gage and Green, 1978, 1979; Röttger, 1979; Gage and Balsley, 1980; Larsen and Röttger, 1982, 1985):

$$
P_{r}=\frac{P_{t} A_{e}^{2}}{4 \lambda^{2} r^{2}} \eta_{\mathrm{ref}}
$$

where $\eta_{\text {ref }}$ is the power reflection coefficient which was studied by VanZandt et al. (1978), VanZandt and Vincent (1983) Gage et al. (1985), assuming that the reflection is contributed by the background value of $M$ and refractive index fluctuations with a scale of half of the radar wavelength. They derived $\eta_{\text {ref }}$ as:

$$
\eta_{\text {ref }}=C M^{2} E(2 k)
$$

where $C$ is a calibration constant which is determined by the radar wavelength and the height resolution of the radar sample volume, while $E(2 k)$ is the spatial density of refractive index variations with a scale of half the radar wavelength in the direction of the radar wave vector (VanZandt and Vincent, 1983). Substituting Eq. (4) into Eq. (8), we find:

$$
\eta_{\text {ref }} \propto \rho^{2} E(2 k) N^{4}
$$

The above relation was investigated by Röttger (1980), and it was further experimentally tested by Larsen and Röttger (1985) and Tsuda et al. (1988). Experimentally, Tsuda et al. (1988) showed that the vertical structure of $\eta_{\text {ref }}$ was mainly determined by $M^{2}$, so the variation of $E(2 k)$ with height seems to be rather small. From Eq. (8), $\eta_{\text {ref }}$ was empirically found to be proportional to $M^{2}$.

Near the tropopause $\eta_{\text {turb }}$ and $\eta_{\text {ref }}$ can be inferred from oblique and vertical echo power, respectively. Considering Eqs. (6) and (9), intensity of both vertical and oblique echoes is closely related to the $N^{2}$ structure near the tropopause, although it is also affected by the behavior of turbulence. We will show, however, in later section that the increase of the vertical echo power and the ratio of vertical to oblique echo power are correlated well with $N^{2}$ profile.

\section{Observation of Vertical and Oblique Echoes 3.1 MU radar observation}

We here briefly introduce the MU radar system, and describe the observation parameters of the clear air echoes. The MU radar in Shigaraki, Shiga prefecture, Japan (34 $51^{\prime}$ $\left.\mathrm{N}, 136^{\circ} 06^{\prime} \mathrm{E}\right)$ is a monostatic pulse Doppler radar with an active phased array system, operating at $46.5 \mathrm{MHz}$ with a peak and average transmitting power of $1 \mathrm{MW}$ and $50 \mathrm{~kW}$, respectively. An outline of the MU radar system was presented by Fukao et al. (1985a, b). The entire observation procedure is supervised by a system-installed radar control- 

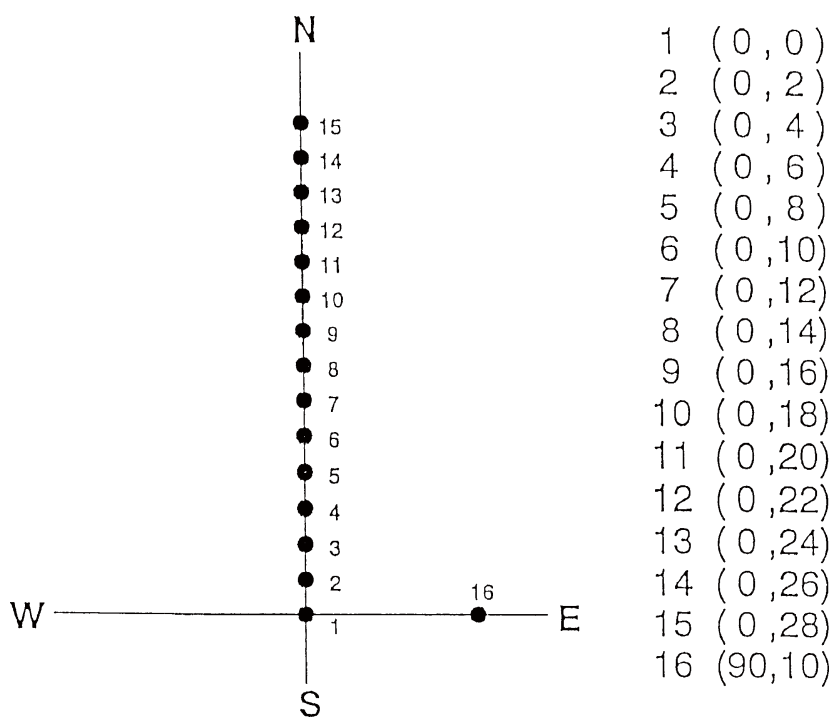

Fig. 1. Antenna beam directions for the MU radar observation on August 24-25, 1991. Full circles denote the beam positions.

ler so that the MU radar is capable of executing a variety of observations.

For convenience we now define the normalized signal-tonoise ratio (SNR), $S_{\theta}$, at a zenith angle, $\theta$, after compensating for the range-squared effect and decrease of the effective antenna area as follows (Tsuda et al., 1997):

$$
S_{\theta}=\frac{1}{\cos ^{2} \theta} \frac{P_{\theta}}{P_{N}}\left(\frac{r}{10 \mathrm{~km}}\right)^{2}
$$

where $P_{\theta}, P_{N}$, and $r$ are the echo power, the noise level and the range in $\mathrm{km}$, respectively. Note that $S_{\theta}$ is normalized to the altitude of $10 \mathrm{~km}$. Thus, the power reflection coefficient, $\eta_{\text {ref }}$, becomes proportional to $S_{\theta}$.

We first present here a case study using data collected for about 25 hours on August 24-25, 1991 for detecting the zenith angle dependence of the echo power. We utilized a set of antenna beam directions; vertical and 14 beam positions at an azimuth angle of $0^{\circ}$ (northward) changing the zenith angle from $2^{\circ}$ to $28^{\circ}$ every $2^{\circ}$ as shown in Fig. 1 . We also steered the 16 -th beam toward east at the zenith angle of $10^{\circ}$ to monitor the orthogonal wind component. Note that the antenna beam was steered sequentially into 16 positions in 16 IPP (inter pulse period), corresponding to about $6 \mathrm{msec}$, so the echoes were sampled essentially at the same time.

\subsection{Zenith angle dependence of echo power}

We describe here the zenith angle variations of echo power revealed by the MU radar observations. We expect that the reflection echo is the strongest in the vertical direction. While at a fairly large zenith angle, we may not receive the reflection any more, but isotropic turbulence scattering becomes dominant. Near the vertical direction both scattering and reflection contribute to the received signal. Therefore, we need to distinguish reflection echoes from isotropic scattering, by investigating zenith angle dependence of echo power.

This has been done by Röttger et al. (1981) using a por-

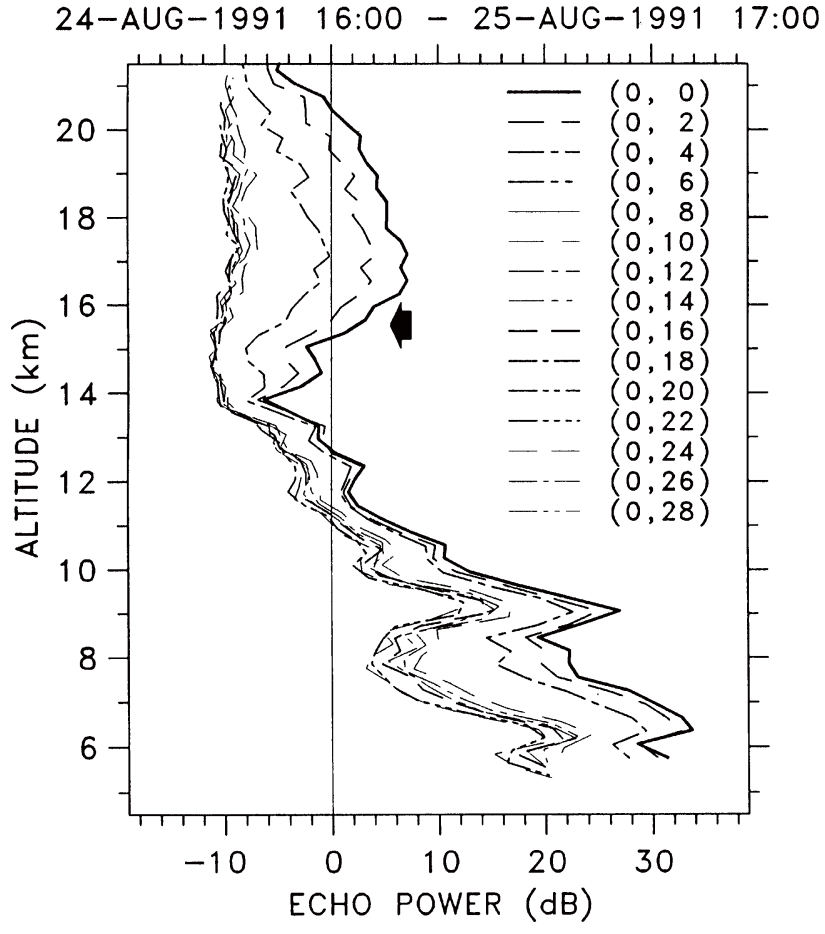

Fig. 2. Mean profiles of normalized echo power in 15 directions observed on August 24-25, 1991. Arrow at $15.5 \mathrm{~km}$ indicates the tropopause observed by a radiosonde at Shigaraki.

table VHF radar in conjunction with the Arecibo radar. More recently, Tsuda et al. (1986) used the MU radar to examine the aspect sensitivity of VHF backscattered power. During these experiments the MU radar scanned successively through a series of beam positions designed to define the angular dependence of backscattered power, $P_{x}$ (where $x$ is the zenith angle) with 2 degree resolution.

Figure 2 shows mean profiles of normalized echo power, $S_{\theta}$ observed on August 24-25, 1991. Note that the tropopause was identified at about $15.5 \mathrm{~km}$ by means of a radiosonde sounding. The vertical echo power was the largest in every height range, showing significant enhancement in comparison with all other oblique echoes. An asymptotic profile of the vertical echo power generally decreased up to $14 \mathrm{~km}$, increased at 14-17 km, reached the maximum at around 17 $\mathrm{km}$, then decreased above. The oblique echoes at zenith angles larger than $6^{\circ}$ showed similar profiles to the vertical echo in the troposphere but their profiles were overlapping with each other above $14 \mathrm{~km}$.

Although the vertical echo power was the largest in the troposphere, the enhancement was dependent on the height ranges. The large aspect sensitivity was recognized below $8.5 \mathrm{~km}$, which was comparable to the stratospheric results, but was smaller at $10-13 \mathrm{~km}$ altitudes. Thus, the reflection mechanism may not be prevailing in the whole troposphere.

Oblique echo power at $2^{\circ}$ and $4^{\circ}$ in Fig. 2 slow a similar height structure with $S_{v}$. But, those at large zenith angles are overlapping with each other, therefore, they could be identified as the level of the isotropic turbulence scattering, which was fairly constant in the stratosphere along height regardless of zenith angles. From this case study, we decided to take a ratio of $S_{v}$ to $S_{10}$, as a measure of the aspect sensi- 

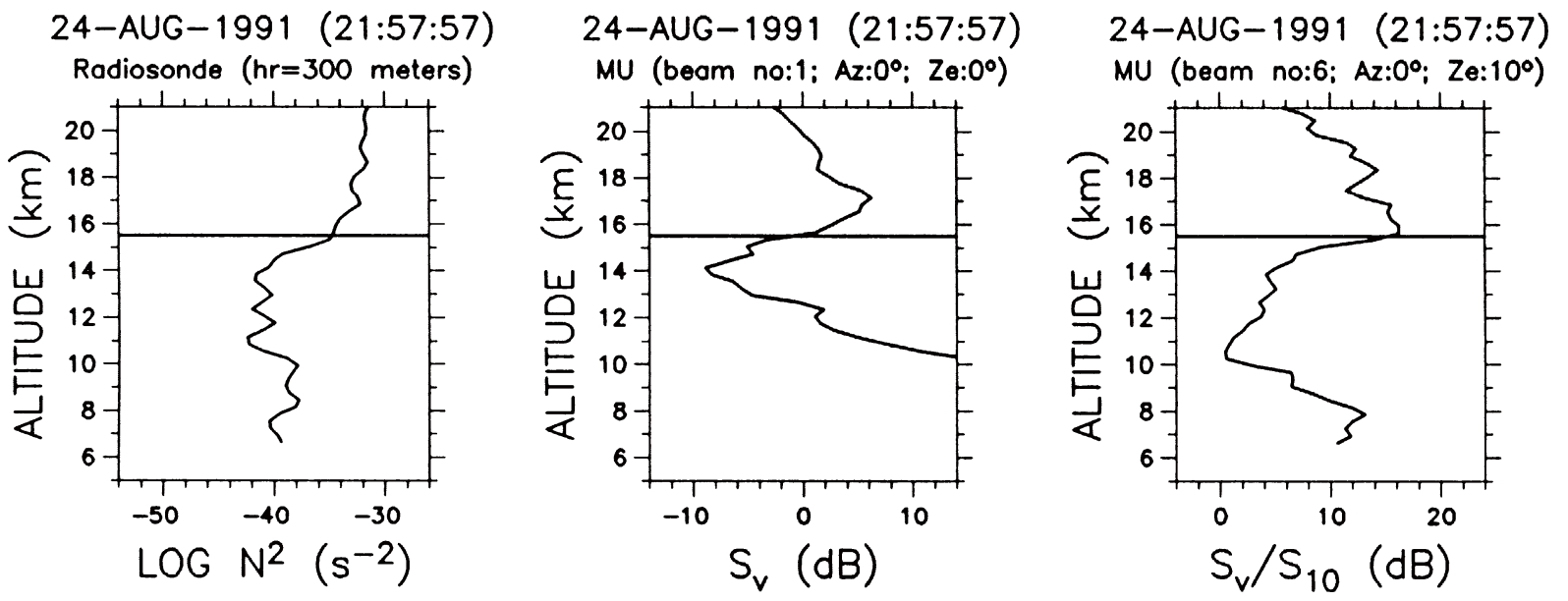

Fig. 3. The $\log$ of $N^{2}$ profile derived from Shigaraki radiosonde data launched at 21:58 LT on August 24, 1991 (left). Also shown the vertical echo power, $S_{v}$ (center) and echo power ratio, $S_{v} / S_{10}$ (right) derived from the MU radar observation in the same time. Solid line at $15.5 \mathrm{~km}$ indicates the tropopause height observed by a radiosonde at Shigaraki.
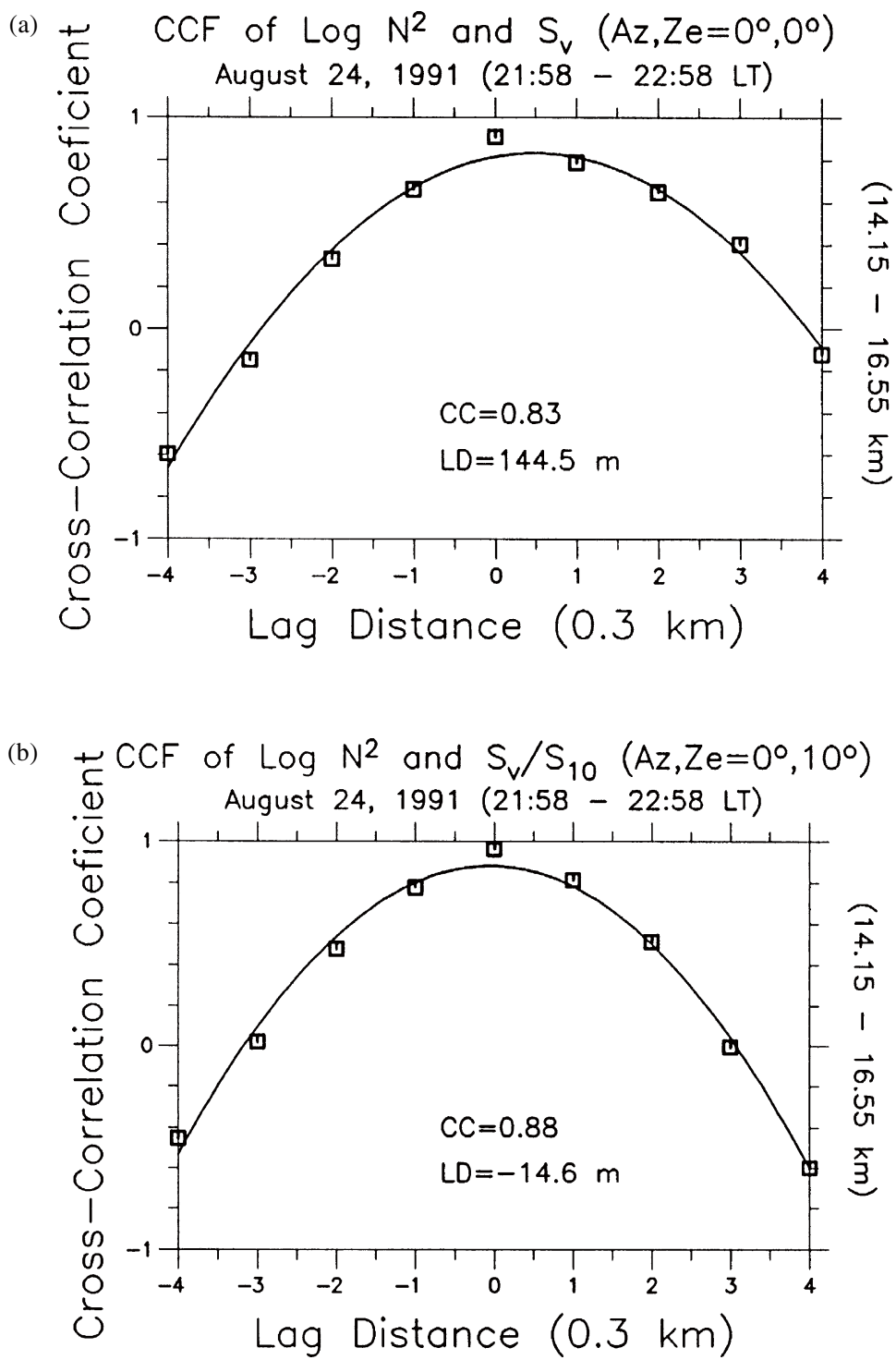

Fig. 4. Normalized cross correlation coefficient between $\log N^{2}$ and (a) $S_{v}$ and (b) $S_{v} / S_{10}$ for observation at 21:58-22:58 LT on August 24, 1991. 
tivity in later sections. It is noteworthy that the power ratio of the vertical echo to the isotropic scattering was small just above the tropopause and in the region above about $20 \mathrm{~km}$ (Hocking et al., 1990), and showed the maximum value of about $20 \mathrm{~dB}$ near $17 \mathrm{~km}$ (Tsuda et al., 1997).

\subsection{Detailed comparison between echo power and $N^{2}$}

From a simultaneous radiosonde profile, we determined the tropopause height according to the conventional definition of tropopause height from World Meteorological Organization (WMO) that is, the tropopause is defined as the lowest level at which temperature lapse rate $(d T / d Z)$ decreases to $2 \mathrm{~K} / \mathrm{km}$ or less and the $d T / d Z$ averaged between this level and any level within the next $2 \mathrm{~km}$ does not exceed $2 \mathrm{~K} / \mathrm{km}$. We present in Fig. 3 profiles of $N^{2}, S_{v}$ and $S_{v} / S_{10}$ determined on August 24, 1991, where a horizontal line at $15.5 \mathrm{~km}$ indicates the tropopause. Note that $S_{v}$ and $S_{v} / S_{10}$ are averaged during 21:58 and 22:58 LT. The tropopause (indicated by a horizontal line in Fig. 3) was associated with a pronounced discontinuity in atmospheric stability, which also coincided with the rapid increase in $S_{v}$ and $S_{v} / S_{10}$.

In order to investigate a correlation between $N^{2}$ and $S_{v}$ or $S_{v} / S_{10}$ in Fig. 3 more clearly, we calculated a CCF (crosscorrelation function) between the parameters in a logarithmic scale, i.e., $\log N^{2}$ and $S_{v}$ and $S_{v} / S_{10}$ in dB with a unit lag distance of $300 \mathrm{~m}$ along altitude. Figures 4(a) and (b) show the CCF at 14.15-16.55 km for $N^{2}$ and $S_{v}$ and $N^{2}$ and $S_{v} / S_{10}$, respectively. The maximum $\mathrm{CCF}$ value was 0.83 and 0.88 at a lag distance of $145 \mathrm{~m}$ and $-15 \mathrm{~m}$, respectively. Note that

(a)

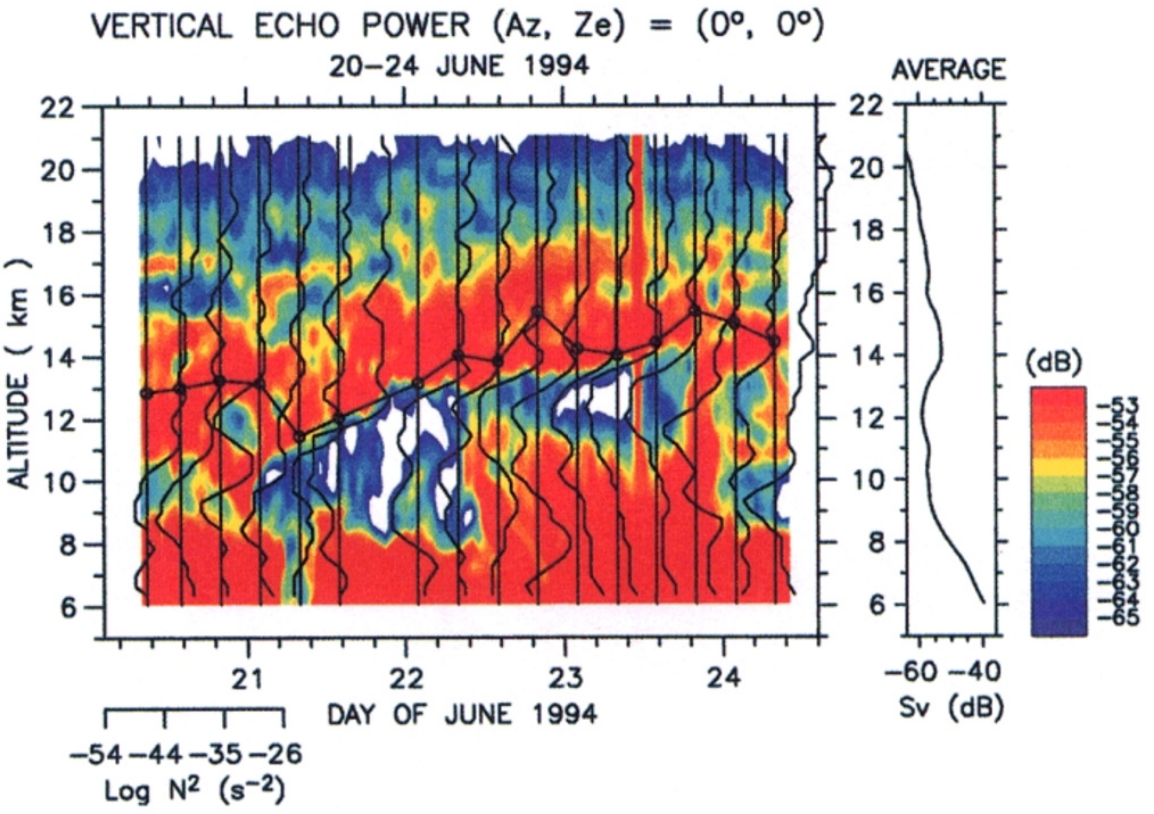

(b)

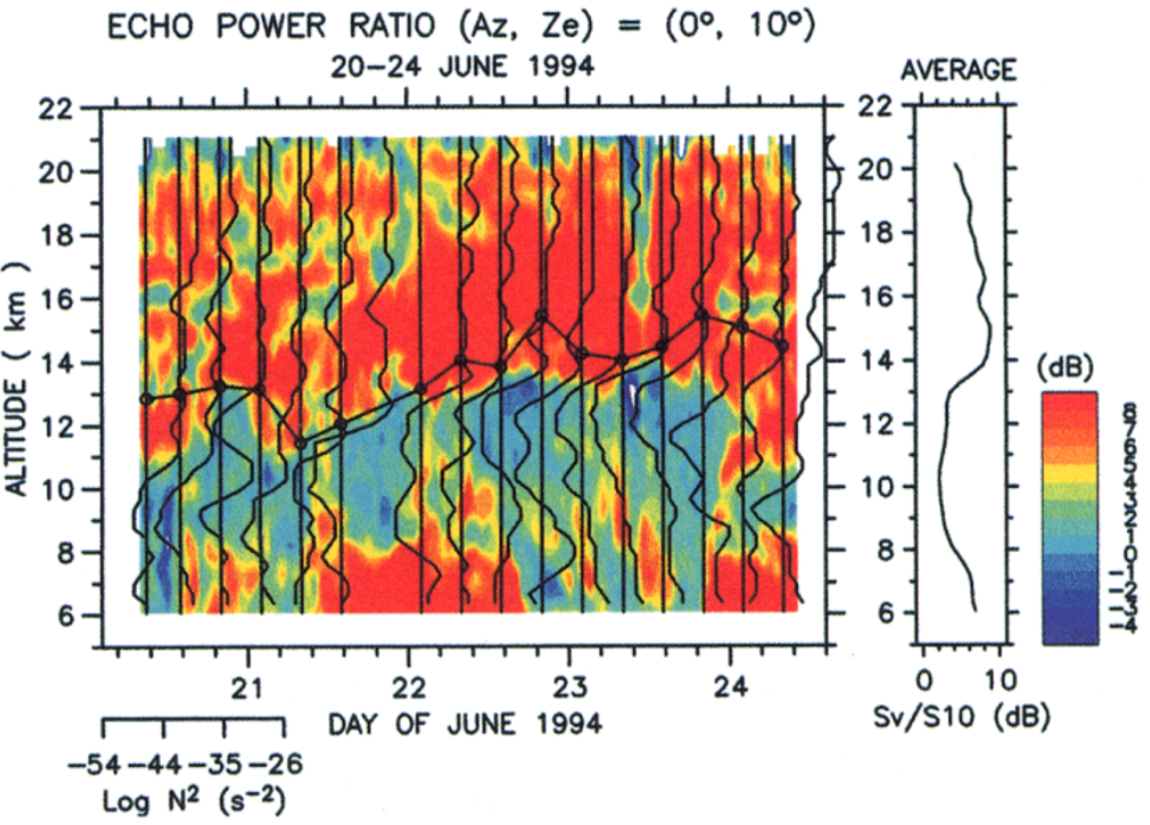

Fig. 5. Time-height section of (a) $S_{v}$ and (b) $S_{v} / S_{10}$ for observation on June 20-24, 1994. Also shown are the $N^{2}$ profiles, and the tropopause height 
a positive lag distance indicates that the enhancement of $S_{v}$ or $S_{v} / S_{10}$ occurred at higher altitude to that in $N^{2}$. We apply this technique to a larger data-set in the next section.

\section{Statistical Comparisons between Echo Power and $N^{2}$}

With the MU radar we have been routinely measuring the troposphere and lower stratosphere for 4-5 days a month since 1984. The antenna beam is pointed into vertical and four orthogonal azimuths at $10^{\circ}$ off the zenith. Among these data-sets, we selected here four periods in February 1987, June 1991, 1993 and 1994 when the temperature profile was simultaneously measured with a radiosonde at the radar site. We launched 7, 10, 8 and 16 radiosondes with an interval of 3-12 hours in the four observation periods, respectively, as summarized in Tables 1-4.

\subsection{Time-height section of $S_{v}$ and $S_{v} / S_{10}$}

We present in Figs. 5(a) and (b) a time-height section of $S_{v}$ and $S_{v} / S_{10}$, respectively, in June 1994, together with a radiosonde profile of $N^{2}$. Note that the $N^{2}$ profiles in Fig. 5 are plotted at the timing of balloon release, although it takes about one hour for a radiosonde to reach the tropopause at about $14-15 \mathrm{~km}$.

On June 21-23 large $S_{v}$ values are generally detected in two height ranges, separated by a region with small $S_{v}$, which is a fairly common behavior of $S_{v}$ (Tsuda et al., 1986). The corresponding $N^{2}$ values in Fig. 5(a) sharply increased near the bottom of the upper region of the large $S_{v}$. While, from June 20 to beginning of June 21 and on June 24, $S_{v}$ was not clearly depressed just below the tropopause, but showed rather irregular height variations. The $N^{2}$ profiles in these periods did not also show a clear enhancement, but, suggested a multiple tropopause structure. From each radiosonde sounding, the tropopause is determined according to the WMO definition, which was normally located just above the sharp increase of $N^{2}$. Enhancement of both $S_{v}$ and $S_{v} / S_{10}$ clearly correlated with time variations of $N^{2}$ structure.

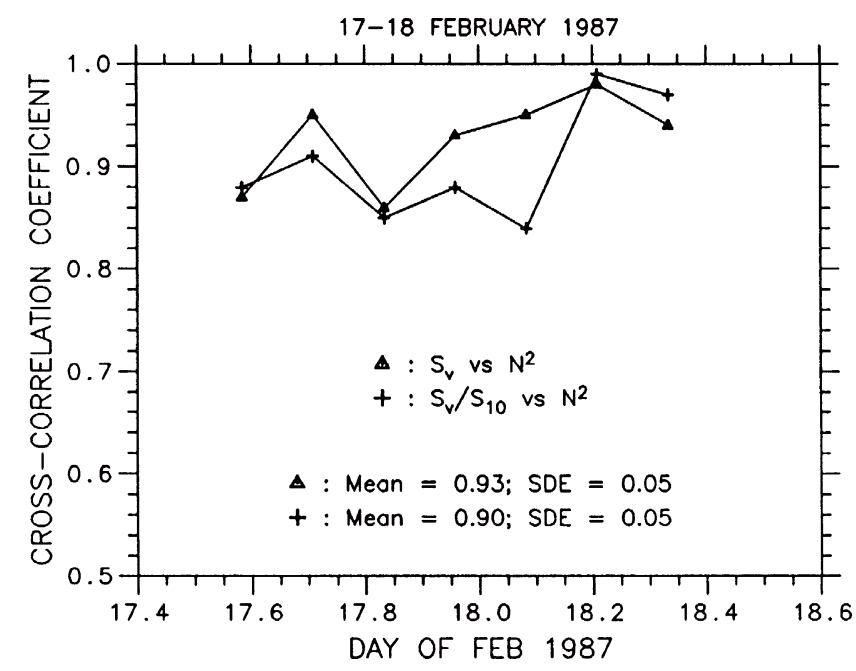

(a)

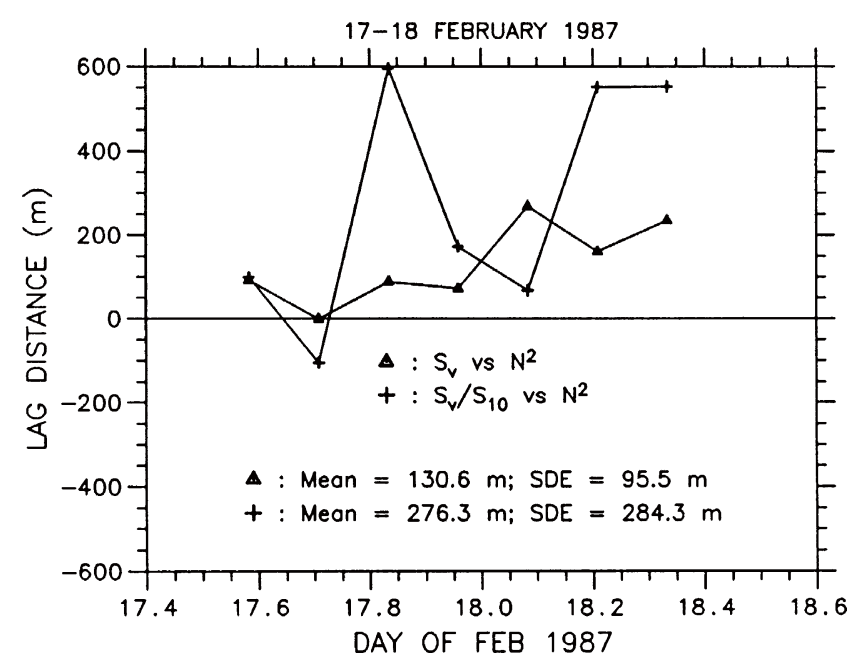

(b)

Fig. 6. Time variation of (a) CCF value and (b) lag distance for $S_{v}$ vs. $N^{2}(\mathbf{\Lambda})$ and $S_{v} / S_{10}$ vs. $N^{2}(+)$ for observation on February 17-18, 1987.

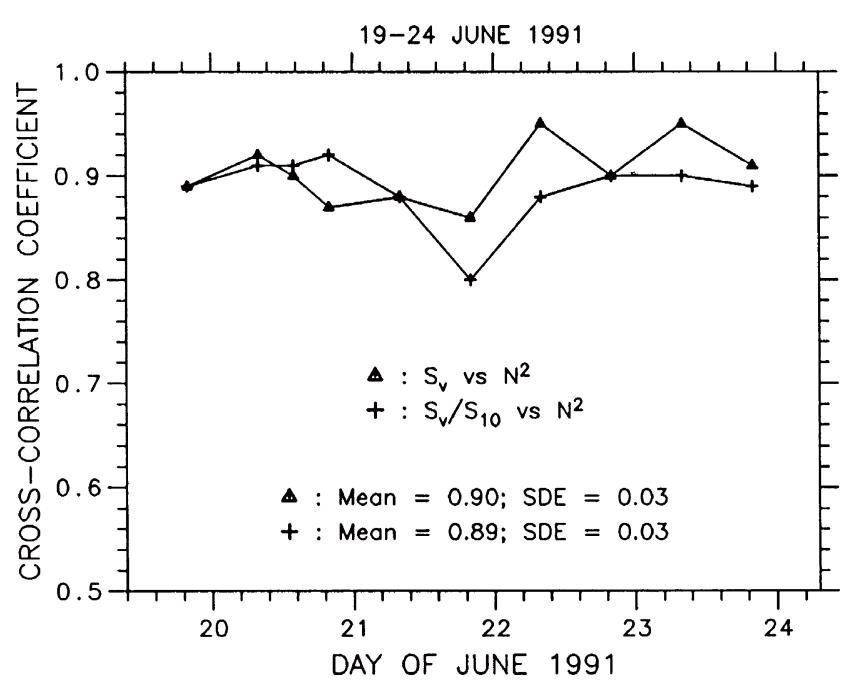

(a)

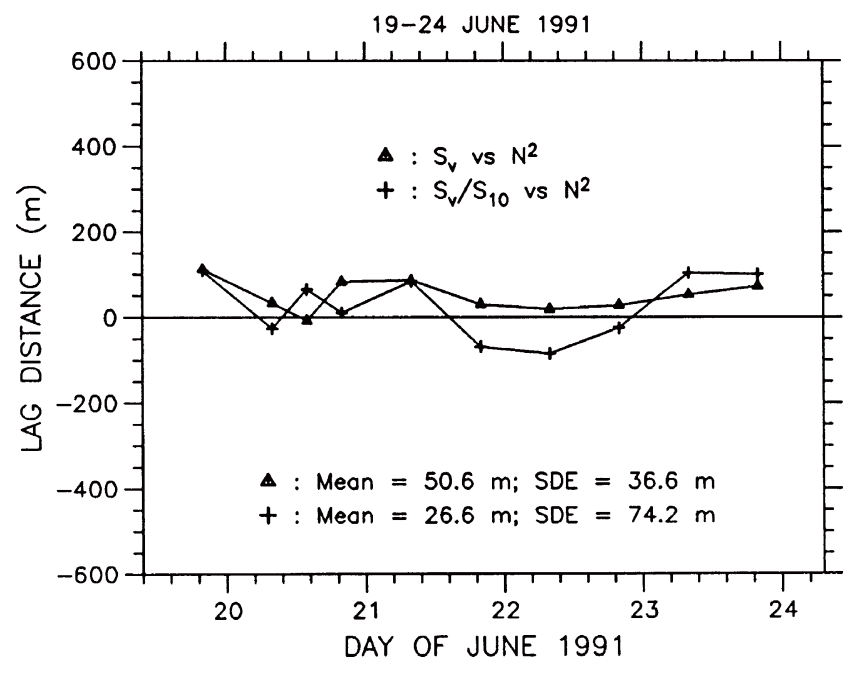

(b)

Fig. 7. The same as Fig. 6, but for on June 19-24, 1991. 


\subsection{CCF analysis between echo power and $N^{2}$}

We here present CCF analysis between $N^{2}$ and $S_{v}$ or $S_{v} / S_{10}$, focusing on the height discrepancy in their enhancement. For an individual $N^{2}$ profile, we compared the $S_{v}$ and $S_{v} / S_{10}$ which are averaged for one hour starting from the balloon launch timing. Then, we selected a height range with a thickness of 2.1 to $4 \mathrm{~km}$ near the sharp increase in the $N^{2}$ profile, then calculated CCF with $N^{2}$ and $S_{v}$ or $S_{v} / S_{10}$. In Tables $1-4$, we summarized the height range, maximum $C C F$ value and lag distance for observations in February 1987, June 1991, 1993 and 1994, respectively.

For the results on February 17-18, 1978, the CCF value and lag distance are shown in Table 1 and Fig. 6. The mean $\mathrm{CCF}$ value during the period was as large as 0.93 and 0.90 for $S_{v}$ and $S_{v} / S_{10}$, respectively, suggesting that these profiles resembled very well near the tropopause. However, the profiles were, on average, displaced vertically by $131 \mathrm{~m}$ and $276 \mathrm{~m}$, respectively, that is, the increase in the echo power occurred slightly higher altitude than for $N^{2}$. The lag dis- tance was generally smaller for $S_{v}$ than for $S_{v} / S_{10}$, further, its standard deviation was smaller for $S_{v}$. On the other hand, the lag distance sometimes exceeded $500 \mathrm{~m}$ for $S_{v} / S_{10}$.

Similar results are presented in Tables $2-4$, and Figs. 79 for data-sets collected in June 1991, 1993 and 1994. The results on June 19-24, 1991, shown in Table 2 and Fig. 7, indicate that the mean CCF value was 0.90 and 0.89 for $S_{v}$ and $S_{v} / S_{10}$, respectively, and the mean height discrepancy was as small as $51 \mathrm{~m}$ and $27 \mathrm{~m}$, with the standard deviation of $37 \mathrm{~m}$ and $74 \mathrm{~m}$, respectively. The agreement between the $N^{2}$ and echo power profiles were very good throughout the observation period.

For observations on June 22-25, 1993, considerable deviations of $\mathrm{CCF}$ values were recognized as in Table 3 and Fig. 8 , therefore, the mean value was only 0.82 and 0.78 for $S_{v}$ and $S_{v} / S_{10}$, respectively. Although the mean lag distance was quite small, i.e., $26 \mathrm{~m}$ and $60 \mathrm{~m}$ for $S_{v}$ and $S_{v} / S_{10}$, respectively, the standard deviation was fairly large, indicating considerable excursions. During the observation period, the

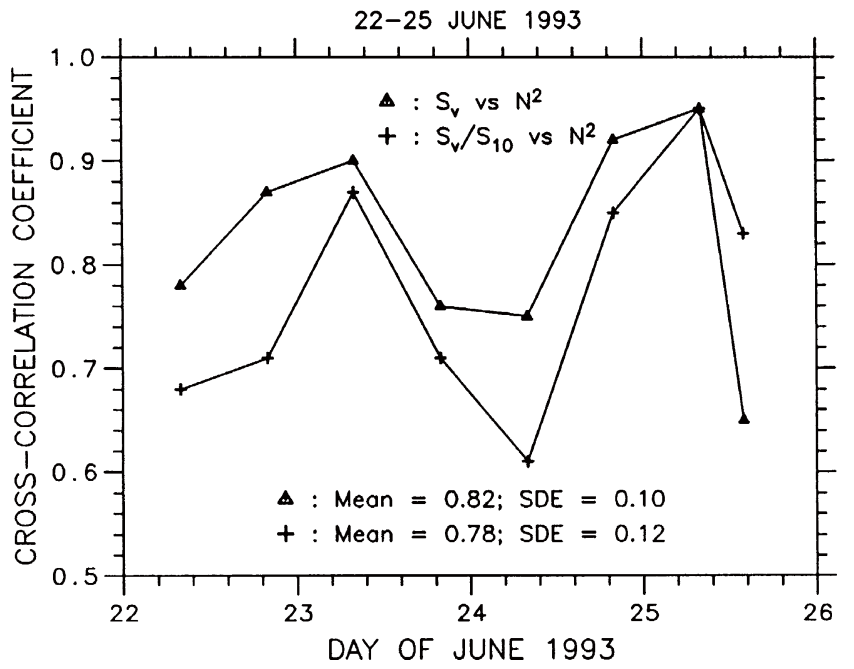

(a)

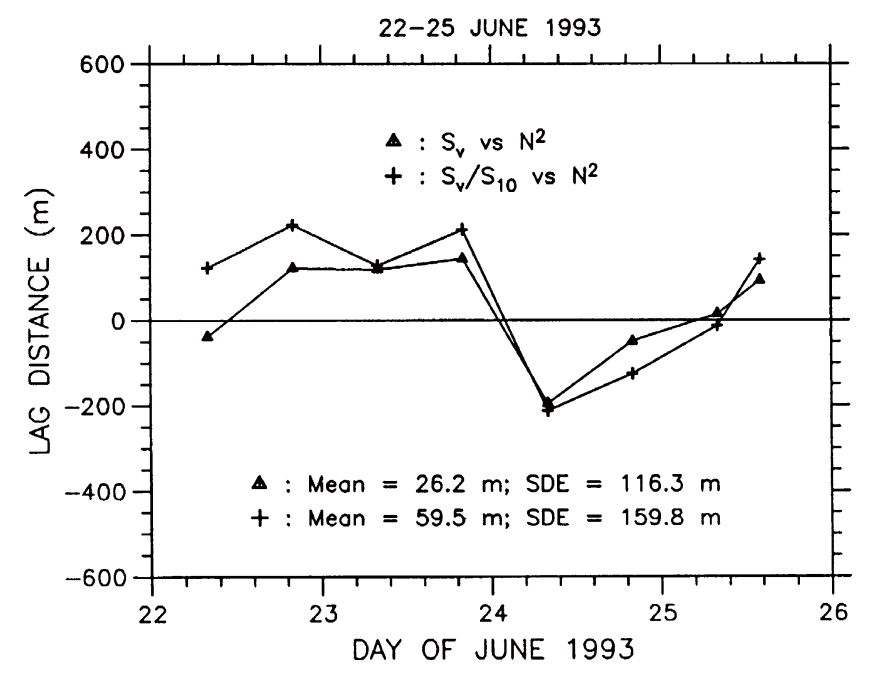

(b)

Fig. 8. The same as Fig. 7, but for on June 22-25, 1993.

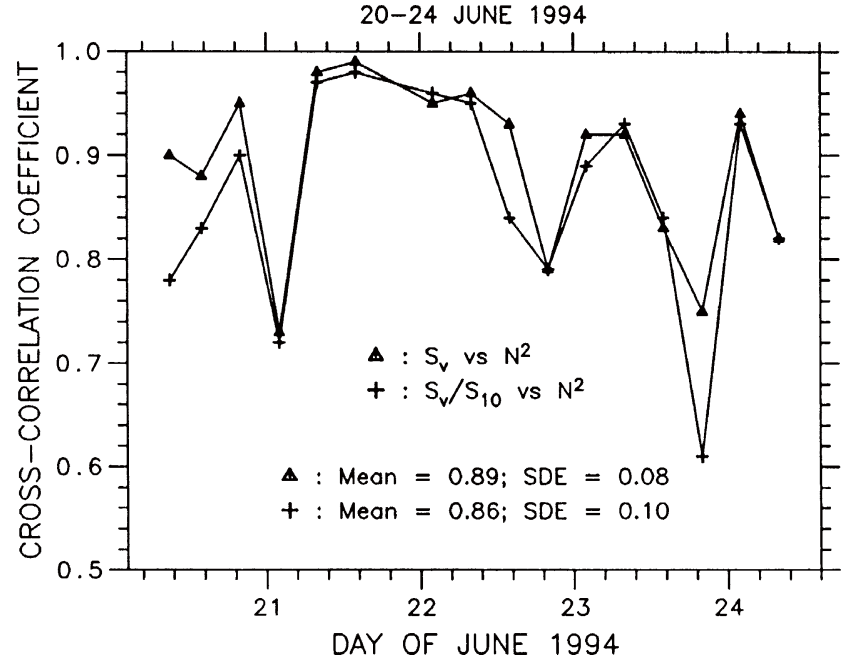

(a)

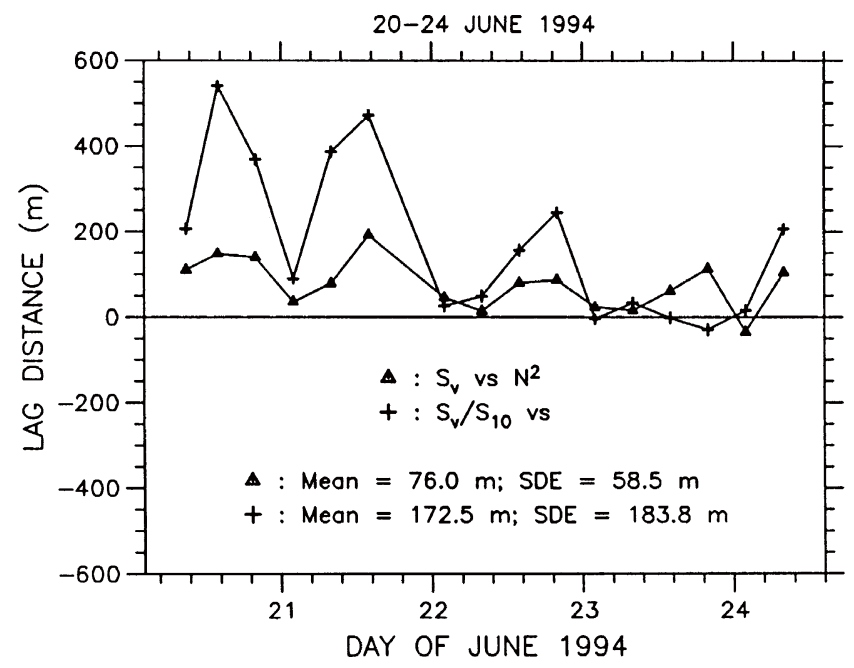

(b)

Fig. 9. The same as Fig. 8, but for on June 20-24, 1994. 
Table 1. Results of CCF analysis for observation on February 17-18, 1987.

\begin{tabular}{|c|c|c|c|c|c|c|}
\hline \multirow{2}{*}{\multicolumn{2}{|c|}{$\begin{array}{c}\text { Balloon launch time } \\
\text { (LT) }\end{array}$}} & \multirow{2}{*}{$\begin{array}{l}\text { Height of CCF analysis } \\
\text { (km) }\end{array}$} & \multicolumn{2}{|c|}{$N^{2}$ vs. $S_{v}$} & \multicolumn{2}{|c|}{$N^{2}$ vs. $S_{v} / S_{10}$} \\
\hline & & & CCF value & lag (m) & CCF value & $\operatorname{lag}(\mathrm{m})$ \\
\hline \multirow[t]{4}{*}{ Feb. 17} & $14: 45$ & $09.95-11.75$ & 0.87 & 92.0 & 0.88 & 98.7 \\
\hline & $17: 20$ & $09.35-11.15$ & 0.95 & -0.8 & 0.91 & -104.4 \\
\hline & $20: 30$ & $09.95-12.35$ & 0.86 & 88.5 & 0.85 & 595.5 \\
\hline & $23: 34$ & $09.65-11.45$ & 0.93 & 71.3 & 0.88 & 172.6 \\
\hline \multirow[t]{3}{*}{ Feb. 18} & $02: 21$ & $08.75-11.15$ & 0.95 & 268.2 & 0.84 & 67.2 \\
\hline & $05: 06$ & $08.75-11.15$ & 0.98 & 160.2 & 0.99 & 551.4 \\
\hline & $18: 17$ & $09.05-12.05$ & 0.94 & 234.8 & 0.97 & 552.9 \\
\hline \multicolumn{3}{|c|}{ Mean value } & 0.93 & 130.6 & 0.90 & 276.3 \\
\hline \multicolumn{3}{|c|}{ Standard deviation } & 0.05 & 95.5 & 0.05 & 284.3 \\
\hline
\end{tabular}

Table 2. The same as Table 1, but for on June 19-24, 1991.

\begin{tabular}{|c|c|c|c|c|c|c|}
\hline \multicolumn{2}{|c|}{$\begin{array}{l}\text { Balloon launch time } \\
\text { (LT) }\end{array}$} & \multirow[t]{2}{*}{$\begin{array}{l}\text { Height of CCF analysis } \\
(\mathrm{km})\end{array}$} & \multicolumn{2}{|c|}{$N^{2}$ vs. $S_{v}$} & \multicolumn{2}{|c|}{$N^{2}$ vs. $S_{v} / S_{10}$} \\
\hline & & & CCF value & $\operatorname{lag}(\mathrm{m})$ & CCF value & lag (m) \\
\hline Jun. 19 & $20: 43$ & $12.35-14.15$ & 0.89 & 114.4 & 0.89 & 107.7 \\
\hline \multirow[t]{3}{*}{ Jun. 20} & $08: 34$ & $12.05-13.85$ & 0.92 & 32.7 & 0.91 & -25.9 \\
\hline & $14: 36$ & $12.95-14.75$ & 0.90 & -7.1 & 0.91 & 64.3 \\
\hline & $20: 20$ & $12.65-14.45$ & 0.87 & 82.7 & 0.92 & 10.8 \\
\hline \multirow[t]{2}{*}{ Jun. 21} & $08: 27$ & $11.75-13.55$ & 0.88 & 85.7 & 0.88 & 83.6 \\
\hline & $20: 27$ & $14.15-15.95$ & 0.86 & 29.4 & 0.80 & -68.2 \\
\hline \multirow[t]{2}{*}{ Jun. 22} & $08: 24$ & $13.25-15.05$ & 0.95 & 18.4 & 0.88 & -84.5 \\
\hline & $20: 16$ & $13.85-15.65$ & 0.90 & 28.0 & 0.90 & -24.7 \\
\hline \multirow[t]{2}{*}{ Jun. 23} & $08: 34$ & $13.25-15.05$ & 0.95 & 52.5 & 0.90 & 103.4 \\
\hline & $20: 25$ & $13.25-15.05$ & 0.91 & 72.1 & 0.89 & 99.9 \\
\hline \multicolumn{3}{|c|}{ Mean value } & 0.90 & 50.6 & 0.89 & 26.6 \\
\hline \multicolumn{3}{|c|}{ Standard deviation } & 0.03 & 36.6 & 0.03 & 74.2 \\
\hline
\end{tabular}

Table 3. The same as Table 2, but for on June 22-25, 1993.

\begin{tabular}{|c|c|c|c|c|c|c|}
\hline \multicolumn{2}{|c|}{$\begin{array}{c}\text { Balloon launch time } \\
\text { (LT) }\end{array}$} & \multirow[t]{2}{*}{$\begin{array}{l}\text { Height of CCF analysis } \\
(\mathrm{km})\end{array}$} & \multicolumn{2}{|c|}{$N^{2}$ vs. $S_{v}$} & \multicolumn{2}{|c|}{$N^{2}$ vs. $S_{v} / S_{10}$} \\
\hline & & & $\mathrm{CCF}$ value & lag (m) & CCF value & $\operatorname{lag}(\mathrm{m})$ \\
\hline \multirow[t]{2}{*}{ Jun. 22} & 08:08 & $11.15-12.95$ & 0.78 & -37.8 & 0.68 & 122.2 \\
\hline & $20: 40$ & $12.35-14.15$ & 0.87 & 121.4 & 0.71 & 222.9 \\
\hline \multirow[t]{2}{*}{ Jun. 23} & $08: 13$ & $12.95-14.75$ & 0.90 & 118.2 & 0.87 & 127.8 \\
\hline & $20: 25$ & $15.05-16.85$ & 0.76 & 143.6 & 0.71 & 211.9 \\
\hline \multirow[t]{2}{*}{ Jun. 24} & $08: 17$ & $15.05-18.05$ & 0.75 & -195.3 & 0.61 & -212.4 \\
\hline & $20: 23$ & $13.25-15.05$ & 0.92 & -48.5 & 0.85 & -125.5 \\
\hline \multirow[t]{2}{*}{ Jun. 25} & $08: 13$ & $13.55-15.35$ & 0.95 & 15.1 & 0.95 & -12.8 \\
\hline & $14: 27$ & $12.95-14.75$ & 0.65 & 92.9 & 0.83 & 141.9 \\
\hline \multicolumn{3}{|c|}{ Mean value } & 0.82 & 26.2 & 0.78 & 59.5 \\
\hline \multicolumn{3}{|c|}{ Standard deviation } & 0.10 & 116.3 & 0.12 & 159.8 \\
\hline
\end{tabular}

$N^{2}$ profiles, except for at 20:40 LT on June 22 and 8:13 LT on June 23, did not indicate a step-wise enhancement. In particular, for three cases between 20:25 LT on June 23 and 20:23 LT on June 24, the $N^{2}$ value gradually increased, which made the CCF analysis less significant, resulting in small $\mathrm{CCF}$ values. Although the corresponding lag distance became negative, its significance seems to be uncertain.

For the comparison at $08: 17 \mathrm{LT}$ on June 24,1993 , the CCF value is as low as of 0.75 and 0.61 for $S_{v}$ and $S_{v} / S_{10}$, re- spectively. Moreover, the increase in $S_{v}$ and $S_{v} / S_{10}$ occurred below the $N^{2}$ enhancement by $150-300 \mathrm{~m}$. Therefore, this particular case suggests that the $N^{2}$ increase is not necessarily accompanied with enhancements of $S_{v}$ and $S_{v} / S_{10}$.

Table 4 and Fig. 9 show the results on June 19-23, 1994, when the largest number of radiosondes were launched. It is noteworthy that CCF values were very similar for $S_{v}$ and $S_{v} /$ $S_{10}$, including two cases at 02:22 LT on June 21 and at 20:32 LT on June 23 , when the CCF value was less than 0.8 . The 
Table 4. The same as Table 3, but for on June 20-24, 1994.

\begin{tabular}{|c|c|c|c|c|c|c|}
\hline \multicolumn{2}{|c|}{$\begin{array}{l}\text { Balloon launch time } \\
\text { (LT) }\end{array}$} & \multirow{2}{*}{$\begin{array}{l}\text { Height of CCF analysis } \\
(\mathrm{km})\end{array}$} & \multicolumn{2}{|c|}{$N^{2}$ vs. $S_{v}$} & \multicolumn{2}{|c|}{$N^{2}$ vs. $S_{v} / S_{10}$} \\
\hline & & & CCF value & lag (m) & CCF value & $\operatorname{lag}(\mathrm{m})$ \\
\hline \multirow[t]{3}{*}{ Jun. 20} & $09: 38$ & $09.65-11.45$ & 0.90 & 110.3 & 0.78 & 206.2 \\
\hline & $14: 29$ & $09.95-12.95$ & 0.88 & 148.3 & 0.83 & 540.0 \\
\hline & $20: 19$ & $09.65-13.85$ & 0.95 & 139.6 & 0.90 & 368.5 \\
\hline \multirow[t]{3}{*}{ Jun. 21} & $02: 22$ & $09.65-13.85$ & 0.73 & 35.9 & 0.72 & 90.1 \\
\hline & $08: 29$ & $09.65-13.85$ & 0.98 & 79.0 & 0.97 & 386.9 \\
\hline & $14: 15$ & $09.65-13.85$ & 0.99 & 191.4 & 0.98 & 472.4 \\
\hline \multirow[t]{4}{*}{ Jun. 22} & $02: 11$ & $12.05-13.85$ & 0.95 & 45.9 & 0.96 & 26.4 \\
\hline & $08: 19$ & $12.05-13.85$ & 0.96 & 14.4 & 0.95 & 49.4 \\
\hline & $14: 17$ & $13.35-14.15$ & 0.93 & 80.0 & 0.84 & 156.3 \\
\hline & $20: 24$ & $12.05-15.05$ & 0.79 & 87.0 & 0.79 & 244.4 \\
\hline \multirow[t]{4}{*}{ Jun. 23} & $02: 15$ & $12.35-14.15$ & 0.92 & 23.6 & 0.89 & -4.5 \\
\hline & $08: 18$ & $12.65-14.45$ & 0.92 & 15.4 & 0.93 & 33.1 \\
\hline & $14: 11$ & $13.25-15.05$ & 0.83 & 61.6 & 0.84 & -1.7 \\
\hline & $20: 32$ & $14.45-16.25$ & 0.75 & 113.6 & 0.61 & -29.4 \\
\hline \multirow[t]{2}{*}{ Jun. 24} & $02: 11$ & $09.65-11.45$ & 0.94 & -34.5 & 0.93 & 15.6 \\
\hline & $08: 14$ & $09.05-10.85$ & 0.82 & 104.5 & 0.82 & 205.9 \\
\hline \multicolumn{3}{|c|}{ Mean value } & 0.89 & 76.0 & 0.86 & 172.5 \\
\hline \multicolumn{3}{|c|}{ Standard deviation } & 0.08 & 58.5 & 0.10 & 183.8 \\
\hline
\end{tabular}

lag distance for $S_{v}$ was persistently small during the observation period, with the mean value of $76.0 \mathrm{~m}$ and its standard deviation of $59 \mathrm{~m}$. However, for four cases on June 20-21, there was a considerable discrepancy in the lag distance between $S_{v}$ and $S_{v} / S_{10}$. That is, the increase in $S_{v} / S_{10}$ appeared higher than for $S_{v}$ by 200-300 m, which simultaneously indicates that the $S_{v} / S_{10}$ enhancement occurred higher than the $N^{2}$ increase. These comparisons suggest that the sharp increase of $S_{v}$ is not simultaneously associated with enhancement of the aspect sensitivity.

The mean CCF values for total of 41 comparisons are shown in Tables $1-4$ were 0.89 and 0.86 for $S_{v}$ and $S_{v} / S_{10}$, respectively. And, the corresponding lag distance was $71 \mathrm{~m}$ and $134 \mathrm{~m}$, with standard deviation of $77 \mathrm{~m}$ and $176 \mathrm{~m}$, respectively. These statistical results indicate that the enhancement of $S_{v}$ and $S_{v} / S_{10}$ normally coincided with the enhancement of $N^{2}$. Further, they occurred slightly higher altitude relative to the step-wise increase of $N^{2}$, except for several cases when the $N^{2}$ did not show a clear enhancement. We found that both $S_{v}$ and $S_{v} / S_{10}$ were correlated well with the increase of $N^{2}$ near the tropopause, although the lag distance was relatively larger for the latter.

Röttger (1980) showed that the echo power increase occurred higher than the tropopause by 300-750 m from SOUSY-VHF-Radar observations. Gage and Green (1979) also found that the radar tropopause was higher than radiosonde results by $300 \mathrm{~m}$. Our analysis, focusing on the detailed variations in this region near the tropopause, clarified that the height difference between $N^{2}$ and $S_{v}$ or $S_{v} / S_{10}$ is as small as $71 \mathrm{~m}$ and $134 \mathrm{~m}$, respectively.

\section{Summary and Conclusions}

This study is mainly concerned with the characteristics of clear air echo intensity near the tropopause, by means of the MU radar observations and simultaneous radiosonde sounding. Earlier theoretical studies on the scattering of VHF radiowaves caused by the refractive index fluctuations of the atmosphere suggest that the echo intensity of both isotropic turbulence scattering and specular reflection is related to $N^{2}$.

We first analyzed a campaign observation on August 2425,1991 , where vertical and oblique echo were obtained at $0^{\circ}-28^{\circ}$ by steering the antenna beam of the MU radar with a step of $2^{\circ}$. The echo power at zenith angles $0^{\circ}, 2^{\circ}$ and $4^{\circ}$ in the lower stratosphere and some regions in the troposphere was significantly larger than that at other larger zenith angles. A ratio of vertical echo power, $S_{v}$, which was the largest in the entire height range, to oblique echo power at $10^{\circ}, S_{v} / S_{10}$, can represent the aspect sensitivity.

We compared profiles of both $S_{v}$ and $S_{v} / S_{10}$ with $N^{2}$, inferred from a radiosonde sounding at the radar site, and found that near the tropopause a large enhancement of both $S_{v}$ and $S_{v} / S_{10}$ coincides with a step-wise increase in $N^{2}$ profile. Cross correlation analysis between $N^{2}$ and $S_{v}$ or $S_{v} /$ $S_{10}$ shows the maximum CCF values of 0.83 and 0.88 , respectively. However, the CCF also suggests that the sharp increase of $S_{v}$ and $S_{v} / S_{10}$ occurred $145 \mathrm{~m}$ higher and $15 \mathrm{~m}$ lower than that for $N^{2}$.

From the monthly MU radar observations in the troposphere and lower stratosphere, routinely continued 4-5 days every month since 1984, we selected the data-sets in February 1987 and June 1991, 1993 and 1994, when radiosondes were launched every 3-12 hours during the radar experiment. Time evolution of $S_{v}$ clearly correlated with the variations of $N^{2}$ profiles. It is noteworthy that the meteorologically defined tropopause was not necessarily coincided with the step-wise increase in $N^{2}$, but, it was determined slightly higher.

We analyzed CCF for total of 41 profiles, and obtained the mean CCF values of 0.89 and 0.86 for $S_{v}$ and $S_{v} / S_{10}$, respectively. The CCF analysis shows that the increase of $S_{v}$ and $S_{v} / S_{10}$ generally occurred slightly higher altitude relative to a sharp increase in $N^{2}$, where the mean lag distance was $71 \mathrm{~m}$ and $134 \mathrm{~m}$, with the standard deviation of $77 \mathrm{~m}$ and $176 \mathrm{~m}$, respectively. However, the lag distance for $S_{v}$ was 
negative for a few cases in each campaign. While, the negative lag distance was more frequently found for $S_{v} / S_{10}$, that is, for 11 out of 41 comparisons its enhancement occurred below the $N^{2}$ increase by $25-150 \mathrm{~m}$.

The observed good relation between $N^{2}$ and the echo power characteristics could be applied to a development of new observational technique for the atmospheric stability structure near the tropopause with good time and height resolution. For further development of this technique, we need to conduct a coordinated observation between the MST radar and a real-time monitoring of temperature structure with, for example, RASS (radio acoustic sounding system) technique.

Acknowledgments. We are grateful to Dr. T. Nakamura of RASC, Kyoto University for his useful suggestions and comments. The MU radar belongs to and is operated by Radio Atmospheric Science Center, Kyoto University.

\section{References}

Balsley, B. B., The MST technique-a brief review, J. Atmos. Terr. Phys., 43, 495-509, 1981.

Fukao, S., T. Sato, T. Tsuda, S. Kato, K. Wakasugi, and T. Makihira, The MU radar with an active phased array system: 1 . Antenna and power amplifiers, Radio Sci., 20, 1155-1168, 1985a.

Fukao, S., T. Sato, T. Tsuda, S. Kato, K. Wakasugi, and T. Makihira, The MU radar with an active phased array system: 2 . In-house equipment, Radio Sci., 20, 1169-1176, 1985b.

Gage, K. S. and B. B. Balsley, On the scattering and reflection mechanisms contributing to clear air radar echoes from the troposphere, stratosphere, and mesosphere, Radio Sci., 15, 407-416, 1980.

Gage, K. S. and J. L. Green, Evidence for specular reflection from monostatic VHF radar observations of the stratosphere, Radio Sci., 13, 991-1001, 1978.

Gage, K. S. and J. L. Green, Tropopause detection by partial specular reflection with VHF radar, Science., 203, 1238-1240, 1979.

Gage, K. S. and J. L. Green, An objective method for the determination of tropopause height from VHF radar observation, J. Appl. Meteorol., 21, 1150-1154, 1982.

Gage, K. S., W. L. Ecklund, and B. B. Balsley, A modified Fresnel scattering model for parameterization of Fresnel returns, Radio Sci., 20, 1493-1501, 1985.

Green, J. L., K. S. Gage, and T. E. VanZandt, Atmospheric measurements by VHF pulsed Doppler radar, IEEE Transactions on Geoscience Electronics, GE-17, 1979.

Hocking, W. K., Measurement of turbulent energy dissipation rates in the middle atmosphere by radar techniques: A review, Radio Sci., 20, 14031422,1985 .

Hocking, W. K. and J. Röttger, Pulse length dependence of radar signal strengths for Fresnel backscatter, Radio Sci., 18, 1312-1324, 1983.

Hocking, W. K., S. Fukao, T. Tsuda, M. Yamamoto, T. Sato, and S. Kato, Aspect sensitivity of stratospheric VHF radio wave scatterers, particularly above $15 \mathrm{~km}$ altitude, Radio Sci., 25, 613-627, 1990.

Hocking, W. K., S. Fukao, M. Yamamoto, T. Tsuda, and S. Kato, Viscosity waves and thermal-conduction waves as a cause of "specular" reflectors in radar studies of the atmosphere, Radio Sci., 26, 1281-1303, 1991.

Holton, J. R., P. H. Haynes, M. E. McIntyre, A. R. Douglass, R. B. Rood, and L. Pfister, Stratosphere-Troposphere Exchange, Rev. Geophys., 33, 403-440, 1995.

Larsen and J. Röttger, VHF and UHF Doppler radars as tools for synoptic research, Bull. Amer. Meteor. Soc., 63, 996-1008, 1982.

Larsen and J. Röttger, Observations of frontal zone and tropopause structures with a VHF Doppler radar and radiosondes, Radio Sci., 20, 1223-1232, 1985.

Ottersten, H., Mean vertical gradient of potential refractive index in turbulent mixing and radar detection of CAT, Radio Sci., 4, 1247-1249, 1969.

Röttger, J., VHF radar observations of a frontal passage, J. Appl. Meteorol., 18, 85-91, 1979.

Röttger, J., Structure and dynamics of the stratosphere and mesosphere revealed by VHF radar investigations, Pure and Appl. Geophys., 118, 494-527, 1980.

Röttger, J., P. Czechowsky and G. Schmidt, First low-power VHF radar observations of tropospheric, stratospheric and mesospheric winds and turbulence at the Arecibo Observatory, J. Atmos. Terr. Phys., 43, 789$800,1981$.

Tatarskii, The effects of the turbulent atmosphere on wave propagation, U.S. Dept. of Commerce, 1971.

Tsuda, T., T. Sato, K. Hirose, S. Fukao, and S. Kato, MU radar observation of the aspect sensitivity of backscattered VHF echo power in the troposphere and lower stratosphere, Radio Sci., 21, 971-980, 1986.

Tsuda, T., P. T. Pay, T. Sato, S. Kato, and S. Fukao, Simultaneous observations of reflection echoes and refractive index gradient in the troposphere and lower stratosphere, Radio Sci., 23, 655-665, 1988.

Tsuda, T., T. E. VanZandt, M. Mizumoto, S. Kato, and S. Fukao, Spectral analysis of temperature and Brunt Väisälä frequency fluctuations observed by radiosondes, J. Geophys. Res., 96, 17265-17278, 1991.

Tsuda, T., T. E. VanZandt, and H. Saito, Zenith-angle dependence of VHF specular reflection echoes in the lower atmosphere, J. Atmos. Terr. Phys., 59, 761-775, 1997.

VanZandt, T. E. and R. A. Vincent, Is VHF Fresnel reflectivity due to lowfrequency buoyancy waves?, Handbook for MAP, Middle Atmosphere Program, University of Illinois, Urbana, 9, 78-80, 1983.

VanZandt, T. E., J. L. Green, K. S. Gage, and W. L. Clark, Vertical profiles of reflectivity turbulence structure constant: Comparison of observations by the Sunset radar with a new theoretical model, Radio Sci., 13, 819-829, 1978

E. Hermawan (e-mail: eddy@kurasc.kyoto-u.ac.jp), T. Tsuda, and T. Adachi 